\title{
Glucose but Not a Mixed Amino Acid Infusion Regulates Plasma Insulin-Like Growth Factor-I Concentrations in Fetal Sheep
}

\author{
M. H. Oliver, J. E. HARDING, B. H. BREIER, P. C. EVANS, AND P. D. GLUCKMAN \\ Department of Paediatrics, University of Auckland, Auckland, New Zealand
}

\begin{abstract}
The influence of fetal glucose and amino acid supply on the regulation of fetal plasma IGF-I levels was investigated in fetuses from starved ewes. Paired maternal and fetal blood samples were taken during an initial 2-d control period, after $48 \mathrm{~h}$ of maternal starvation, during a 24-h fetal infusion of glucose $(n=6)$ or an amino acid mixture (Synthamin 17, $n=5$ ) with continued starvation, and after 48 h of maternal refeeding. After 48 h of starvation, maternal and fetal plasma IGF-I, insulin, and blood glucose fell significantly in both groups compared with control values (IGF-I for glucose group: maternal, -18.53 \pm 6.60 ; fetal, $-5.23 \pm 1.81 \mathrm{nmol} / \mathrm{L}$; amino acid group: maternal, $-18.2 \pm 6.97$, fetal, $-5.12 \pm 1.61 \mathrm{nmol} / \mathrm{L}$; both $p<0.05$ ). Fetal glucose but not mixed amino acid infusion raised fetal plasma IGF-I, insulin, and blood glucose to near control values (glucose group fetal IGF-I, $-1.77 \pm$ 1.98; amino acid group, $-5.93 \pm 2.22 \mathrm{nmol} / \mathrm{L}$; both $p<$ 0.05). Maternal plasma IGF-I remained depressed during glucose infusion $(-16.33 \pm 8.32 \mathrm{nmol} / \mathrm{L})$, but continued to fall in the amino acid group $(-21.41 \pm 8.20 \mathrm{nmol} / \mathrm{L}, p<$ $0.05)$. After $48 \mathrm{~h}$ of maternal refeeding, all values had returned to near control values for both groups (glucose group IGF-I: maternal, $-5.2 \pm 3.86$; fetal, $0.01 \pm 2.2$ nmol/L; amino acid group: maternal, $-11.66 \pm 3.2$; fetal, $-0.70 \pm 2.61 \mathrm{nmol} / \mathrm{L})$. We conclude that in the ovine fetus glucose may have a more important role than amino acids in the regulation of fetal plasma IGF-I. (Pediatr Res 34: $62-65,1993$ )
\end{abstract}

The regulation of fetal growth appears to involve the interplay of fetal substrate supply and fetal endocrine status $(1,2)$. The nature of this interplay is poorly understood. The role of endocrine IGF-I in fetal growth is probably of particular importance (1-3). In postnatal life, circulating IGF-I is markedly influenced by substrate supply, falling during starvation and rising rapidly upon refeeding (4). Carbohydrates and amino acids are important in the postnatal regulation of endocrine IGF-I (4). However, the relative importance of these substrates in the regulation of fetal endocrine IGF-I remains unclear.

We have previously shown that in the pregnant sheep $72 \mathrm{~h}$ of maternal starvation causes a fall in both maternal and fetal plasma IGF-I levels (5). Glucose infusion to the mother for $4 \mathrm{~h}$ followed by maternal refeeding led to the restoration of both

Received July 1, 1992; accepted February 10, 1993.

Correspondence: P. D. Gluckman, Developmental Physiology Laboratory, Department of Paediatrics, University of Auckland, Private Bag 92019, Auckland, New Zealand.

Supported by grants from the Health Research Council (New Zealand), the National Child Health Research Foundation (New Zealand), Auckland Medical Research Foundation (New Zealand), and the Foundation for the Newborn (New Zealand). maternal and fetal plasma IGF-I levels, suggesting that circulating IGF-I in the fetus was also regulated by substrate supply. However, in these experiments it was not possible to determine whether the observed changes in fetal IGF-I levels were influenced directly by fetal blood glucose or indirectly by changes in the mother. Furthermore, fetal blood glucose levels obtained after the glucose infusion were very high and any effects on circulating IGF-I levels may have been pharmacologic rather than physiologic. It was also possible that maternal ad libitum refeeding meant that substrates other than glucose had an influence on fetal and maternal IGF-I levels.

The objective of this study was to characterize the substrate regulation of fetal plasma IGF-I by directly infusing glucose or an amino acid mixture into the fetus at physiologic levels during continued maternal starvation.

\section{MATERIALS AND METHODS}

Eleven Coopworth/Border cross-bred ewes were acclimatized to feeding regimens and laboratory conditions at least $1 \mathrm{wk}$ before surgery. The ewes consumed at least $1200 \mathrm{~g}$ of feed concentrates/d (NRM Multi-Feed Sheep Nuts, NRM Feeds Limited, Auckland, New Zealand). Ad libitum feeding with barley straw was provided for bulk. At 118 to 123 d gestation, polyvinyl catheters were surgically inserted, with the ewes under halothane anesthesia, into the tarsal veins and arteries of both fetal hind legs and the carotid artery and jugular vein of each mother. After surgery, the ewes were allowed at least $5 \mathrm{~d}$ to recover before experiments were begun.

The experimental protocol consisted of a 2-d control period followed by $3 \mathrm{~d}$ of maternal starvation. After $48 \mathrm{~h}$ of maternal starvation, the fetuses were infused i.v. with glucose $(n=6 ; 1$ $\mathrm{mL}$ bolus then $2 \mathrm{~mL} / \mathrm{h} 50 \%$ glucose solution) or mixed amino acids $[n=5 ; 1 \mathrm{~mL}$ bolus then $3.5 \mathrm{~mL} / \mathrm{h} 10 \%$ amino acid solution (Synthamin 17, Baxter Pharmaceuticals Ltd., New South Wales, Australia; see Table 1 for composition) for $24 \mathrm{~h}$. The infusion rates were equivalent to estimated fetal consumption rates (6). Paired maternal and fetal blood samples were taken daily in the morning before normal feeding time and in the afternoon $8 \mathrm{~h}$ later. On the day of the fetal infusion, additional samples were taken $4 \mathrm{~h}$ before and immediately before the start of the infusion, and then at $+2,+4,+8$, and $+24 \mathrm{~h}$ of the infusion. The ewes were refed ad libitum for $48 \mathrm{~h}$ after the completion of the infusions. Blood samples were collected in sterile heparinized syringes and placed in tubes on ice, and blood glucose was measured within $30 \mathrm{~min}$ using a YSI 2300 STAT glucose analyzer (Yellow Springs Instrumenı Co., Yellow Springs, $\mathrm{OH}$ ). The remaining blood was centrifuged at $4^{\circ} \mathrm{C}$ and the plasma stored at $-20^{\circ} \mathrm{C}$ until RIA for IGF-I and insulin. In the case of the amino acid infusions, blood aliquots were immediately deproteinized on ice with tungstic acid and then centrifuged. The supernatants were stored at $-80^{\circ} \mathrm{C}$ until assay. Total blood amino acids were measured by the method of Frame et al. (7) and 
Table 1. Composition of amino acid mixture Synthamin 17*

\begin{tabular}{lc}
\hline Essential amino acids $(\mathrm{mg} / \mathrm{mL})$ & 7.3 \\
L-Leucine & 6.0 \\
L-Isoleucine & 5.8 \\
L-Lysine & 5.8 \\
L-Valine & 5.6 \\
L-Phenylalanine & 4.8 \\
L-Histidine & 4.2 \\
L-Threonine & 4.0 \\
L-Methionine & 1.8 \\
L-Tryptophan & \\
Nonessential amino acids $(\mathrm{mg} / \mathrm{mL})$ & 20.7 \\
L-Alanine & 11.5 \\
L-Arginine & 10.3 \\
Glycine & 5.0 \\
L-Serine & 6.8 \\
L-Proline & 0.4 \\
L-Tyrosine & \\
\hline
\end{tabular}

* Data supplied by manufacturer.

Russell (8), which was modified (9) to use smaller volumes of blood $(100 \mu \mathrm{L})$ and reagents. The mean coefficient of intraassay variation was $<4 \%$, and the maximum coefficient of interassay variation was $5.1 \%$. Experimental protocols were approved by the institutional Animal Ethics Committee.

Plasma IGF-I was measured by double antibody RIA (10) using rabbit antiserum to recombinant human metIGF-I (878/ 4) at a final titer of $1: 250000$. The antiserum has a cross-reaction with IGF-II and insulin of $<0.05 \%$ and $<0.001 \%$, respectively. In this assay system, the minimal detectable dose was $0.06 \mathrm{ng} /$ tube and the half displacement dose was $0.40 \mathrm{ng} /$ tube. Before immunoassay, plasma samples were subjected to acid-ethanol cryo-precipitation extraction. We discovered during our validation procedure that some fetal plasma samples from animals undergoing starvation failed to displace parallel to the standard curve after the acid-ethanol cryo-precipitation. We have previously shown that residual IGF binding protein-2 is markedly elevated during fetal starvation (11) and failure to remove this binding protein during extraction caused the loss of parallel displacement. Because our antiserum $(878 / 4)$ has very low crossreactivity with IGF-II, we assessed whether an analogous approach to the IGF-II immunoassay used by Blum et al. (12) could be used for the IGF-I assay. After the cryo-precipitation step, recombinant human IGF-II (batch 099EM9, Eli Lilly and Company, Indianapolis, IN) was added ( $25 \mathrm{ng} / \mathrm{tube}$ ) to the assay buffer. Using this system, the recovery of IGF-I added to fetal plasma before extraction was $85.0 \pm 8.9 \%(n=10)$ and the recovery of IGF-I added to maternal plasma before extraction was $84.2 \pm 7.6 \%(n=7)$. Selected fetal and maternal samples from this experiment obtained during control, starvation, and refeeding periods were also subjected to acid gel chromatography on a Sephadex G-75 (Pharmacia, Uppsala, Sweden) column before IGF-I RIA (10) as an alternative method of removing the interfering influence of binding proteins. The IGF-I values obtained after the acid gel chromatography showed a high correlation $(r=0.84$; slope: $y=0.992 x+26.365)$ with IGF-I values obtained after the cryo-precipitation and IGF-II addition procedures. The intraassay coefficient of variation was $5.0 \%$ and the interassay coefficient of variation was $9.8 \%$. Plasma IGF-I concentrations are expressed in terms of the international reference preparation (ORR oIGF-I, batch $87 / 518$ ).

Plasma insulin was assayed as described previously (13) using guinea pig anti-ovine insulin antiserum (GC4) at a titer of 1:150000. The cross-reactivity with IGF-I and IGF-II was less than $0.01 \%$. The intraassay coefficient of variation was $6.7 \%$ and the interassay coefficient of variation was $11.5 \%$.

Because interanimal variation of IGF-I, insulin, and amino nitrogen was high, all data were normalized relative to the control values for each animal (mean of four samples taken over the 2 control d). Comparison between the groups was performed by two-way analysis of variance with repeated measures, and for differences at specific time points factorial analysis of variance with Sheffe's correction for multiple comparisons was used. For statistical comparison between absolute values obtained in the control period, at the end of infusion, and after maternal ad libitum refeeding, paired $t$ tests were used. Significant differences were accepted at the $5 \%$ level.

\section{RESULTS}

During $48 \mathrm{~h}$ of starvation, there was a significant fall $(p<$ 0.05 ) in fetal and maternal blood glucose, plasma insulin, and IGF-I levels in both groups (Table 2).

Intravenous infusion of glucose to the fetus caused significant increases $(p<0.05)$ in fetal blood glucose (Fig. 1), plasma insulin (Fig. 2), and IGF-I (Fig. 3, Table 2). Maternal blood glucose, plasma insulin, and IGF-I did not change significantly during the fetal glucose infusion. After the completion of the infusion, $48 \mathrm{~h}$ of maternal ad libitum refeeding caused fetal and maternal blood glucose, plasma insulin, and IGF-I to return to near control values (Table 2).

Fetal i.v. infusion of the amino acid mixture caused a small increase in fetal amino nitrogen (Fig. 4) but not in fetal blood glucose (Fig. 1), plasma insulin (Fig. 2), or IGF-I (Fig. 3 and Table 2). Maternal blood amino nitrogen, glucose, and plasma insulin remained depressed during the fetal infusion and plasma IGF-I continued to decrease beyond the level at $48 \mathrm{~h}(p<0.05)$. After $48 \mathrm{~h}$ of maternal ad libitum refeeding, fetal and maternal blood glucose, plasma insulin, and IGF-I returned to near control values (Table 2). Fetal blood amino nitrogen decreased $(p<$ 0.05 ) below the last value obtained during the amino acid infusion and maternal blood amino nitrogen remained depressed after maternal refeeding.

Fetal blood glucose, plasma insulin, and IGF-I were significantly higher $(p<0.05)$ during glucose than during mixed amino acid infusion (Figs. 1-4). Maternal blood glucose was higher after $8 \mathrm{~h}$ of glucose infusion to the fetus than after amino acid infusion, but this difference was no longer apparent after $24 \mathrm{~h}$ of infusion. There were no other measured differences between the experimental groups at any time.

\section{DISCUSSION}

This study demonstrated that fetal glucose, rather than fetal amino acids or maternal substrates, is an important regulator of circulating fetal IGF-I. This is consistent with the postulated importance of both fetal substrate supply and endocrine IGF-I in the regulation of fetal growth (1). It suggests a possible mechanism by which fetal growth is adjusted to avoid excessive fetal substrate consumption at times when supply is restricted. In contrast, plasma IGF-I could enhance growth when substrate supply is not the limiting factor. However, additional specific experiments would be required to test these hypotheses directly.

It is not obvious from our study why glucose rather than amino acids appears to be the important regulator of fetal IGF$\mathrm{I}$, inasmuch as the converse is reported in postnatal animals (4). It has been previously reported (14) that for amino acids to stimulate fetal insulin release there has to be a sufficient supply of fetal glucose. The lack of influence of the amino acid mixture on fetal plasma insulin in our study would support this earlier finding, and perhaps the same regulation exists for fetal plasma IGF-I. Another possible reason could be that the composition of amino acids may not have been appropriate and that greater concentrations of specific amino acids in the infusate may have elicited plasma insulin and IGF-I responses. It is also possible that specific amino acids may regulate fetal plasma IGF-I independent of effects on fetal plasma insulin. Our measurement of total amino nitrogen did not allow us to detect changes in individual amino acids during these experiments that may be 
Table 2. Plasma hormone and blood metabolite concentrations during maternal starvation, fetal infusion, and maternal refeeding*

\begin{tabular}{|c|c|c|c|c|}
\hline & $\begin{array}{c}\text { Glucose } \\
(\mathrm{mM})\end{array}$ & $\begin{array}{c}\mathrm{AN} \\
(\mathrm{mM})\end{array}$ & $\begin{array}{c}\text { IGF-I } \\
(\mathrm{nmol} / \mathrm{L})\end{array}$ & $\begin{array}{c}\text { Insulin } \\
(\mathrm{nmol} / \mathrm{L})\end{array}$ \\
\hline \multicolumn{5}{|l|}{ Fetal } \\
\hline \multicolumn{5}{|l|}{ Glucose infusion } \\
\hline Control & $0.8 \pm 0.2$ & $7.4 \dagger$ & $13.5 \pm 3.6$ & $0.33 \pm 0.1$ \\
\hline 48-h fasting & $0.5 \pm 0.1 \ddagger$ & $6.0 \dagger$ & $7.9 \pm 3.1 \ddagger$ & $0.11 \pm 0.09 \ddagger$ \\
\hline 24-h infusion & $0.8 \pm 0.2 \ddagger$ & $5.3 \dagger$ & $11.36 \pm 2.85 \ddagger$ & $0.24 \pm 0.08 \ddagger$ \\
\hline 48-h refeeding & $0.9 \pm 0.3$ & $4.8 \dagger$ & $13.13 \pm 4.23$ & $0.22 \pm 0.08$ \\
\hline \multicolumn{5}{|c|}{ Amino acid infusion } \\
\hline Control & $0.9 \pm 0.2$ & $8.2 \pm 0.3$ & $10.23 \pm 1.76$ & $0.26 \pm 0.08$ \\
\hline 48-h fasting & $0.6 \pm 0.2 \ddagger$ & $8.2 \pm 0.7$ & $5.11 \pm 1.55 \ddagger$ & $0.11 \pm 0.02 \ddagger$ \\
\hline 24-h infusion & $0.5 \pm 0.2$ & $8.9 \pm 0.4$ & $3.93 \pm 0.77$ & $0.14 \pm 0.05$ \\
\hline 48-h refeeding & $0.9 \pm 0.5$ & $7.3 \pm 0.8 \ddagger$ & $9.2 \pm 3.77 \ddagger$ & $0.29 \pm 0.17$ \\
\hline \multicolumn{5}{|l|}{ Maternal } \\
\hline \multicolumn{5}{|l|}{ Glucose infusion } \\
\hline Control & $2.4 \pm 0.3$ & $4.5 \uparrow$ & $43.64 \pm 11.5$ & $0.64 \pm 0.43$ \\
\hline 48-h fasting & $1.4 \pm 0.5 \ddagger$ & $3.4 \dagger$ & $12.99 \pm 1.94 \ddagger$ & $\mathrm{BDL}$ \\
\hline 24-h infusion & $1.4 \pm 0.3$ & $3.7 \dagger$ & $15.37 \pm 2.15$ & $0.07 \pm 0.04$ \\
\hline 48-h refeeding & $2.5 \pm 0.4 \ddagger$ & $2.8 \dagger$ & $26.31 \pm 8.1 \ddagger$ & $0.55 \pm 0.15 \ddagger$ \\
\hline \multicolumn{5}{|c|}{ Amino acid infusion } \\
\hline Control & $2.5 \pm 0.4$ & $4.3 \pm 0.7$ & $28.44 \pm 8.37$ & $0.39 \pm 0.19$ \\
\hline 48-h fasting & $1.4 \pm 0.4 \ddagger$ & $3.6 \pm 0.4$ & $11.86 \pm 4.08 \ddagger$ & $0.07 \pm 0.05 \ddagger$ \\
\hline 24-h infusion & $1.2 \pm 0.4$ & $3.4 \pm 0.1$ & $8.66 \pm 2.69 \ddagger$ & BDL \\
\hline 48-h refeeding & $2.5 \pm 1.3$ & $3.6 \pm 0.3$ & $14.42 \pm 6.29$ & $0.76 \pm 0.47$ \\
\hline
\end{tabular}

* Values are means \pm SD. AN, amino nitrogen; BDL, below detectable limit of assay (approximately $0.05 \mathrm{nmol} / \mathrm{L}$ ).

$\dagger$ Data available from only one animal.

$\ddagger$ Significantly different from previous value $(p<0.05)$.
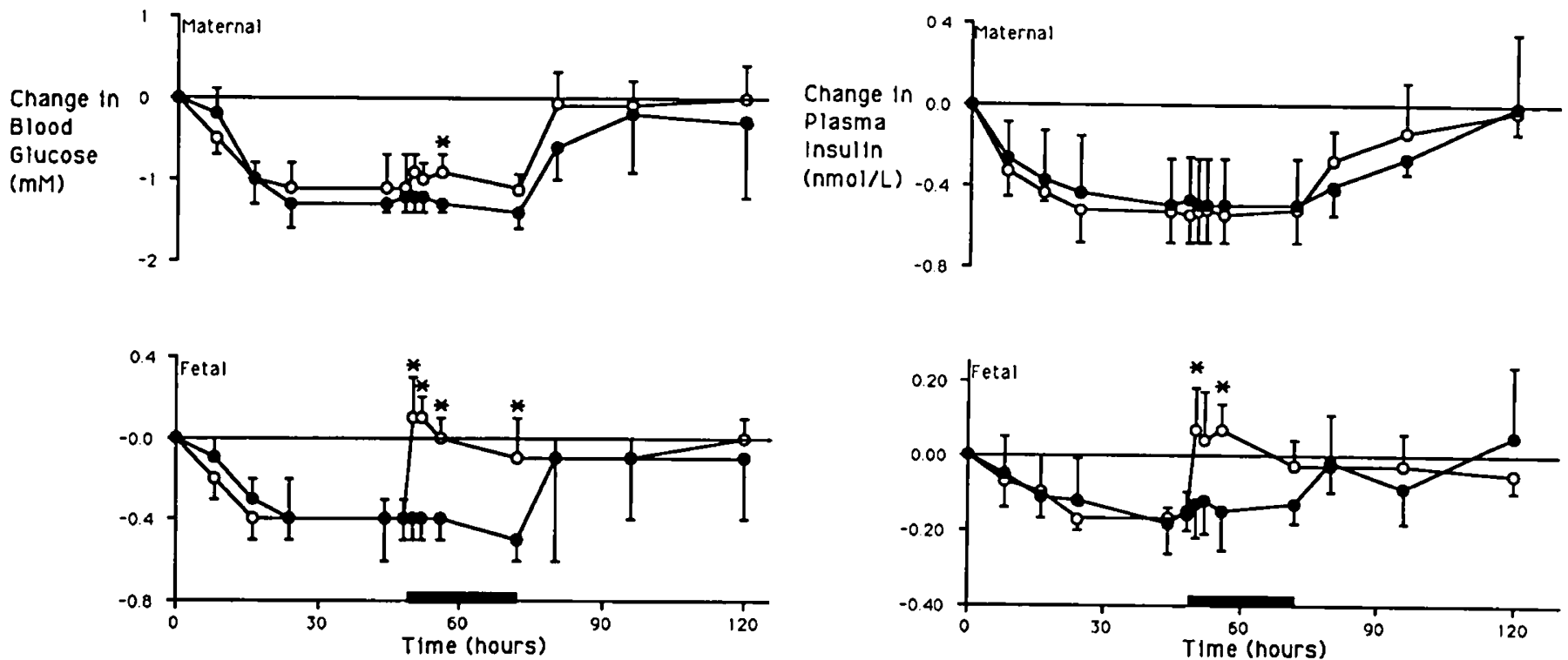

Fig. 1. Maternal and fetal blood glucose responses to maternal starvation and fetal infusion of glucose or amino acids. Values are mean \pm $\mathrm{SD}$, calculated for the change from mean baseline glucose level for each animal. Starvation began at $0 \mathrm{~h}$. The solid bar indicates i.v. infusion to the fetus. Open circles, glucose infusion $(n=6)$; filled circles, amino acid infusion $(n=5)$. *, Significantly different between groups $(p<0.05)$.

important in this regard. Because fetal blood amino nitrogen did not fall during maternal starvation and the mixed amino acid infusion also caused little change in total amino nitrogen levels, it is also possible that larger changes in fetal amino acid levels would result in changes in fetal IGF-I concentrations. However, amino acids cross the placenta by active transport mechanisms, and changes in circulating fetal amino acid levels are relatively small over the range of common physiologic and pathologic variations in fetal supply. Teleologically, if fetal IGF-I levels are important in the regulation of fetal growth, it is more appropriate for these levels to respond to changes in fetal glucose, which not

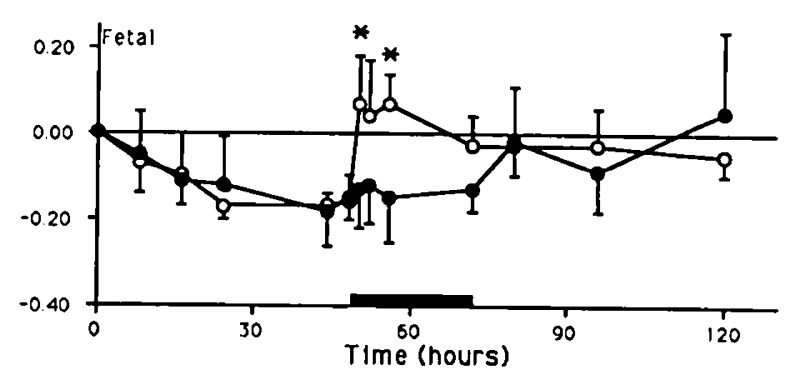

Fig. 2. Maternal and fetal plasma insulin responses to maternal starvation and fetal infusion of glucose or amino acids. Values are mean \pm $\mathrm{SD}$, calculated for the change from mean baseline plasma insulin level for each animal. Starvation began at $0 \mathrm{~h}$. The solid bar indicates i.v. infusion to the fetus. Open circles, glucose infusion $(n=6)$; filled circles, amino acid infusion $(n=5)$. ${ }^{*}$, Significantly different between groups $(p$ $<0.05$ )

only is the principle substrate for fetal metabolism (6), but also fluctuates over a wider range of concentrations in response to changes in substrate supply from the mother. We have recently shown (unpublished observations) that an increase in circulating fetal IGF-I increases amino acid transport across the placenta to the fetus. Therefore, an elevation in fetal glucose may indirectly lead to increased IGF-mediated amino acid transfer.

It is interesting to note that infusion of glucose to the fetus also arrested the decline in maternal plasma IGF-I, but in the mothers of the mixed amino acid-infused fetuses, plasma IGF-I 

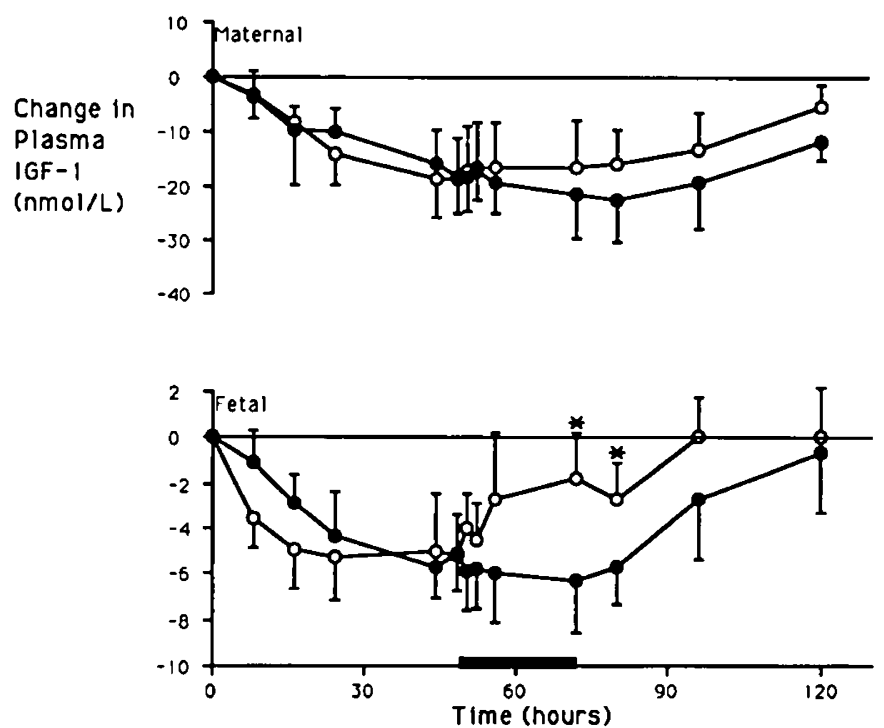

Fig. 3. Maternal and fetal plasma IGF-I responses to maternal starvation and fetal infusion of glucose or amino acids. Values are mean \pm $\mathrm{SD}$, calculated for the change from mean baseline plasma IGF-I level for each animal. Starvation began at $0 \mathrm{~h}$. The solid bar indicates i.v. infusion to the fetus. Open circles, glucose infusion $(n=6)$; filled circles, amino acid infusion $(n=5){ }^{*}$, Significantly different between groups $(p<$ $0.05)$.
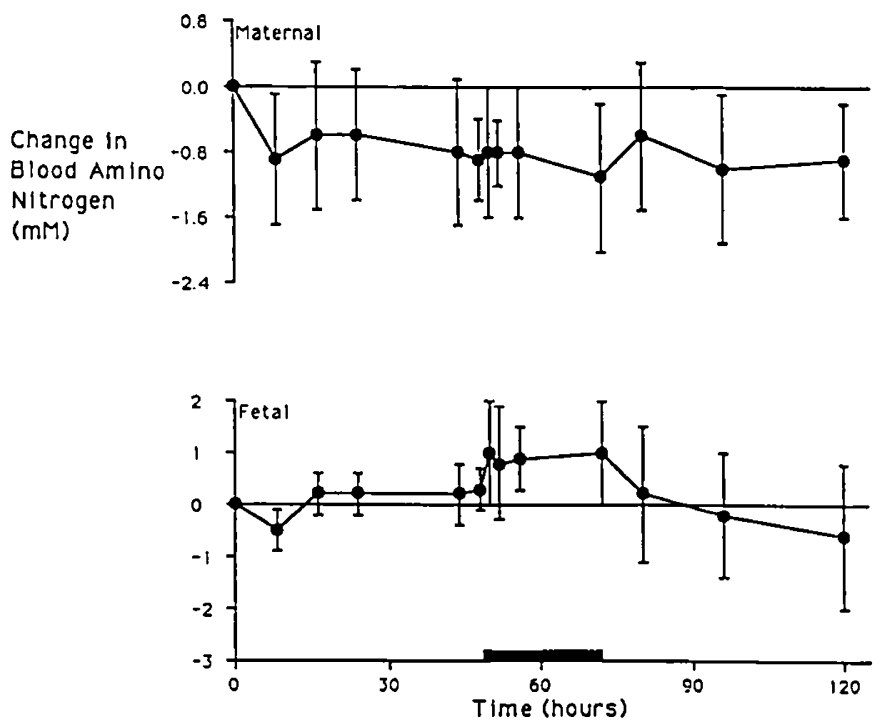

Fig. 4. Maternal and fetal blood amino nitrogen responses to maternal starvation and fetal amino acid infusion. Values are mean $\pm S D$, calculated for the change from mean baseline amino nitrogen level for each animal. Starvation began at $0 \mathrm{~h}$. The solid bar indicates i.v. amino acid infusion to the fetus.

continued to fall. Because the conceptus normally consumes approximately $25 \%$ of total maternal glucose production in the sheep (15), infusion of glucose to the fetus in this experiment may have reduced fetal demand for maternal glucose and thus prevented a further fall in maternal plasma IGF-I, whereas in the mixed amino acid-infused group, fetal glucose demand continued. Thus, not only did fetal glucose supply appear to regulate fetal IGF-I levels, but indirectly it had a potentially important feedback influence on maternal IGF-I levels. Alternatively, if the placenta is an additional source of IGF-I for the maternal circu- lation, as has been suggested previously for the fetal circulation (16), then an elevation in fetal glucose may affect placental IGFI production and perhaps maternal plasma IGF-I levels.

Although this study suggests that fetal glucose is an important regulator of circulating fetal IGF-I, it is possible that insulin is also important in this regard. In these experiments, glucose but not mixed amino acid infusion raised fetal plasma insulin levels. Thus, insulin may mediate, in whole or more likely in part, the effect of glucose on circulating fetal IGF-I. Fetal pancreatectomy results in low fetal levels of both insulin and IGF-I (17), and fetal hyperinsulinemia leads to elevated fetal somatomedin-like activity (18-20). Indeed, it is possible that the role of insulin in fetal growth may include the maintenance of circulating IGF-I as well as the promotion of substrate uptake. Additional studies are required to clarify the relative roles of glucose and insulin in the observed nutritional regulation of fetal circulating IGF-I.

Acknowledgments. The authors thank Christine Gibson, Fiona Ffolliott-Powell, Li Liu, and Mark Vickers for their technical assistance.

\section{REFERENCES}

1. Owens JA 1991 Endocrine and substrate control of fetal growth: placental and maternal influences and insulin-like growth factors. Reprod Fertil Dev 3:501-517

2. Chard T 1989 Hormonal control of growth in the human fetus. J Endocrinol 123:3-9

3. Gluckman PD, Breier BH, Oliver MH, Harding J, Bassett N 1990 Fetal growth in late gestation-a constrained pattern of growth. Acta Paediatr Scand [Suppl] 367:105-110

4. Clemmons DR, Underwood LE 1991 Nutritional regulation of IGF-I and IGF binding proteins. Annu Rev Nutr 11:393-412

5. Bassett NS, Oliver MH, Breier BH, Gluckman PD 1990 The effect of maternal starvation on plasma insulin-like growth factor I concentrations in the late gestation ovine fetus. Pediatr Res 27:401-404

6. Battaglia FC, Meschia G 1978 Principle substrates of fetal metabolism. Physiol Rev 58:499-527

7. Frame EG, Russell JA, Wilhelmi AE 1943 The colorimetric estimation of amino nitrogen in blood. J Biol Chem 149:255-270

8. Russell JA 1944 Note on the colorimetric determination of amino nitrogen. J Biol Chem 156:467-468

9. Evans PC, Ffolliott-Powell FM, Harding JE 1993 A colorimetric assay for amino nitrogen in small volumes of blood; reaction with $\beta$-napthoquinone sulfonate. Anal Biochem 208:334-337

10. Breier BH, Gallaher BW, Gluckman PD 1991 Radioimmunoassay for insulinlike growth factor-1: solutions to some potential problems and pitfalls. J Endocrinol 128:347-357

11. Gallaher BW, Breier BH, Oliver MH, Harding JE, Gluckman PD 1992 Ontogenic differences in the nutritional regulation of circulating IGF binding proteins in sheep plasma. Acta Endocrinol (Copenh) 126:49-54

12. Blum WF, Ranke MB, Bierich JR 1988 A specific radioimmunoassay for insulin-like growth factor II: the interference of IGF binding proteins can be blocked by excess IGF-1. Acta Endocrinol (Copenh) 118:374-380

13. Breier BH, Gluckman PD, Bass JJ 1988 Plasma concentrations of insulin-like growth factor and insulin in the infant calf: ontogeny and influence of altered nutrition. J Endocrinol 119:43-50

14. Fowden AL 1980 Effects of adrenaline and amino acids on the release of insulin in the sheep fetus. J Endocrinol 87:113-121

15. Hay Jr WW, Sparks JW, Wilkening RB, Battaglia FC, Meschia FC 1983 Partition of maternal glucose production between conceptus and maternal tissues in sheep. Am J Physiol 245:E347-E350

16. Iwamoto KS, Chernausek SD, Murray MA 1991 Regulation of plasma insulinlike growth factor (IGF-I) by oxygen and nutrients in fetal sheep. Second International IGF Symposium, San Francisco. University of California, San Francisco, A48(abstr)

17. Gluckman PD, Butler JH, Comline R, Fowden A 1987 The effects of pancreatectomy on the plasma concentrations of insulin-like growth factors 1 and 2 in the sheep fetus. J Dev Physiol 9:79-88

18. Hill DJ, Milner RDG 1980 Increased somatomedin and cartilage metabolic activity in rabbit fetuses injected with insulin in utero. Diabetologia 19:143147

19. Spencer GSG, Hill DJ, Garssen GJ, Macdonald AA, Colenbrander B 1983 Somatomedin activity and growth hormone levels in body fluids of the fetal pig: effect of chronic hyperinsulinaemia. J Endocrinol 96:107-114

20. Heinze E, Nguyen TC, Vetter U, Fussgänger RD 1982 Interrelationship of insulin and somatomedin activity in fetal rats. Biol Neonate 41:240-245 